Ганна Кашина, кандидат педагогічних наук Національний педагогічний університет імені М.П. Драгоманова

\title{
МЕТОДИКА ОЦНЮВАННЯ ЯКОСТІ ЕЛЕКТРОННИХ НАВЧАЛЬНИХ РЕСУРСІВ У СИСТЕМІ ПІСЛЯДИПЛОМНОЇ ПЕДАГОГІЧНОЇ ОСВІТИ
}

У дослідженні розглядаються питання проблеми оцінювання якості електронних освітніх ресурсів. Ї̈ складність підвищується за рахунок того, щзо інтерактивний мультимедійний контент відображає найновіші досягнення в галузі інформаиійних систем та комп'ютерної техніки на зміст навчальної дисципліни, утворюючи інновачійні якості електронних освітніх ресурсів. Тому шляхами підвищення якості оцінювання електронних освітніх ресурсів є розвиток системи критерїв, вдосконалення кваліметрї, уніфікація технологій і прочедур, додавання очінки споживачів освітньої послуги.

Ключові слова: електронний навчальний ресурс; експертиза; експертна оцінка; інтегральна оцінка

Постановка проблеми. Однією із складових навчального процесу у сучасній педагогіці $є$ відкриті освітні ресурси, які використовують для забезпечення навчально-виховного процесу за класно-урочною, самостійною, індивідуальною та дистанційними формами навчання. Наразі вирішується завдання ефективного використання відкритих електронних освітніх ресурсів для конструювання та організації взаємодії всіх суб'єктів навчального процесу.

Із застосуванням і створенням відкритих електронних освітніх ресурсів, які дозволяють керувати груповою, самостійною та індивідуальною роботою на принципово новому організаційному рівні, пов'язані перспективи розвитку різних технологій навчання. Уміння викладача застосовувати електронні освітні ресурси у практиці навчання та виховання є складовою його компетентності в галузі використання інформаційних i комунікаційних технологій - IKTкомпетентності.

Проблема оцінювання якості електронних освітніх ресурсів виникла практично одночасно з появою перших видань на компактдисках і ресурсів в Інтернеті. Складність проблеми оцінювання якості сучасних відкритих електронних освітніх ресурсів підвищується за рахунок того, що інтерактивний мультимедійний контент відображає вплив останніх досягнень у галузі інформаційних систем та комп'ютерної техніки на зміст навчальної дисципліни, утворюючи інноваційні якості електронних освітніх ресурсів.

До теперішнього часу завдання оцінювання якості електронних освітніх ресурсів вирішувалися виключно на основі експертної оцінки. Комплексна експертиза $[1 ; 2]$ передбачала тривимірну оцінку електронних освітніх ресурсів, яка основана на технологічній, змістовій і дизайн-ергономічній експертизі. Проте оцінки експертів мають певні проблеми: нечіткість критеріїв, слабка 
кваліметрія, невизначеність технології, суб'єктивність експерта. У той же час наразі експертна оцінка $є$ єдино можливою. Тому очевидним способом підвищення об'єктивності оцінювання електронних освітніх ресурсів є розвиток системи критеріїв, вдосконалення кваліметрії, уніфікація технологій і процедур.

Створення новітніх електронних освітніх ресурсів додало новий поштовх у розвитку кваліметрії і критеріїв оцінювання різних якостей електронного освітнього контенту. Значною обставиною у цьому процесі $\epsilon$ те, що ресурси нового покоління уніфіковані за більшістю аспектів: єдине функціональне середовище, визначена архітектура електронного навчального модуля.

Вирішення проблеми оцінювання якості електронних освітніх ресурсів в Україні розпочалося із затвердження Положення про електронні освітні ресурси - Наказ МОН України від 01.10.2012 № 1060 [3], у якому узагальнено визначення поняття електронних освітніх ресурсів, здійснено класифікацію електронних навчальних ресурсів, порядок їх розроблення та впровадження.

Загальновідомо, що якість освіти істотно залежить від якості навчальних посібників та підручників, якими користується учень, студент, викладач. Для контролю та забезпечення якості електронної навчальної літератури необхідно проводити експертизу та сертифікацію електронних навчальних видань: оцінювання відповідності певним вимогам щодо змісту, структури, інформаційного наповнення, функціональних та навчальних можливостей, сучасних наукових положень. А тому актуальним стає розроблення критеріїв сертифікації електронних освітніх ресурсів з визначенням надалі рівня їх якості.

Сертифікація у технічному регулюванні $\epsilon$ дія третьої сторони, яка доводить, чи забезпечується необхідна впевненість у тому, що належно ідентифікована продукція, процес чи послуга відповідають конкретному стандарту або іншому нормативному документу [4]. Тому вважливим є для забезпечення контролю якості оцінювання електронних освітніх ресурсів сформулювати:

1. Перелік вимог до електронних освітніх ресурсів.

2. Розробити методику сертифікації електронних освітніх ресурсів на підставі положень чинних правил сертифікації. ·

3. Для реалізації можливості порівняння різних електронних навчальних видань розробити методику оцінювання рівня їхньої якості на засадах теорії кваліметрії як оцінювання ступеня відповідності встановленим вимогам.

Аналіз останніх досліджень Питання оцінювання якості електронних освітніх ресурсів досліджуються вченими у різних напрямах. Так змістовнометодичні показники, дизайн-ергономічність та техніко-технологічність розглядались у працях В. Роберт [7], І.Е. Вострокнутова [3]; проблеми впровадження електронних освітніх ресурсів у навчальний процес відображено В.Ю. Биковим, В.В. Лапінським [1], В.П. Вембер [2]; критерії якості електронних освітніх ресурсів для платформ дистанційного навчання визначені Н.В. Морзе , О.Г. Глазуновою [6]; критерії оцінювання електронних навчальних інформаційних ресурсів розкрито Г.М. Кравцовим [5]; педагогічне 
проектування особистісно-орієнтованих електронних освітніх ресурсів досліджено В.В. Гурим [4].

Аналіз результатів дослідження свідчить про недостатню вивченість проблеми визначення критеріїв оцінювання електронних освітніх ресурсів.

Метою статті $\epsilon$ розгляд проблеми оцінювання якості електронних освітніх ресурсів.

Методи дослідження: аналіз, узагальнення, систематизація педагогічної літератури щодо оцінювання якості електронних освітніх ресурсів у вищих навчальних закладах.

Виклад основного матеріалу У визначенні якості електронних освітніх ресурсів важливими $є$ критерії. На думку В.В. Кравцова [5] до критеріїв оцінювання електронного ресурсу має бути віднесено: авторство матеріалу, повноту представлення навчального матеріалу, відповідність матеріалу світовим стандартам (IMS, SCORM, IEEE та ін.), відповідність змісту робочої програми, повноту методичного забезпечення дисципліни, ступінь використання ресурсу, структурування матеріалу (зміст, лекції, розділи, глави, параграфи), ергономічність тексту (ефективність, розуміння, сприйняття), використання гіпертекстових посилань, наочність матеріалу (форматування тексту, графіки, ілюстрації, фото), використання мультимедійних модулів, інтерактивних систем, тестових завдань, стандартних форматів файлів, відповідність матеріалу рівню знань студента, вільний доступ до матеріалу. Кожний критерій оцінюється 0,3 або 5 балами. Якість електронних освітніх ресурсів визначається середнім значенням усіх критеріїв.

Інший підхід пропонують Н.В. Морзе та О.Г. Глазунова [6]. Розроблена ними критеріальна рамка оцінювання електронного освітнього ресурсу на базі мультимедійної платформи дистанційного навчання включає такі складові: робочу програму, графік навчання, шкалу оцінювання, друковані та інтернет джерела, термінологічний словник, оголошення, теоретичний матеріал, практичні (лабораторні роботи), завдання для самостійної роботи, модульний контроль, підсумкову атестацію. Деталізація критеріїв здійснюється у розрізі структурно-функціональної, науково-змістовної та методичної експертиз. Вони виділяють шість основних характеристик якості електронного освітнього ресурсу: функціональність, надійність, зручність, ефективність, супровід та можливість перенесення навчального матеріалу (мобільність). Оцінювання якості електронного освітнього ресурсу має враховувати індивідуалізацію, диференціацію та самостійне навчання, можливість застосування для різних типів занять (засвоєння нових знань, набуття умінь та навичок, узагальнення та систематизація знань, контроль, коригування знань, комбінований урок, забезпечувати наочність навчального матеріалу тощо).

Проте, загальними недоліками різних методів оцінювання електронних освітніх ресурсів можна вважати:

- занадто велику кількість критеріїв оцінювання, що ускладнює його процес; ·

- дублювання змісту вимог; · 
- подані методи моніторингу та тестування не систематизують вимог; ·

- методи структурної експертизи дають змогу оцінити лише структуру, а не змістове, методичне та наукове наповнення електронних освітніх ресурсів; ·

- складність алгоритмів оцінювання.

Загальні вимоги щодо електронних навчальних ресурсів містяться у нормативних документах, зокрема [9-11]:

1. ДСТУ 7157:2010. Інформація та документація. Видання електронні. Основні види та вихідні відомості. - Чинний від 2010-07-01.

2. ДСТУ 4861:2007 Інформація та документація. Видання. Вихідні відомості. - Чинний від 2009.01.01.

3. ДСТУ 3017-95 Видання. Основні види. Терміни та визначення. - Чинний від 1996-01-01.

Розроблення та впровадження електронних освітніх ресурсів у навчальний процес сьогодні $є$ загальносвітовою тенденцією. Тому у вирішенні проблеми оцінювання якості електронних освітніх ресурсів важливими $є$ міжнародні стандарти для інформаційно-комунікаційних засобів навчального призначення та співпраця міжнародної організації зі стандартизації ISO з міжнародними організаціями й комітетами, зокрема, 3 Міжнародною електротехнічною комісією IEC. Міжнародний стандарт ISO/IEC 19796:2005 "Інформаційні технології навчання, освіта, підготовка. Менеджмент якості, забезпечення якості та метрики" [12] є базисом для опису, порівняння, аналізу, менеджменту якості та підходів до забезпечення якості в цій сфері. Він $є$ інструментом для зіставлення вже відомих підходів та їх узгодження на основі загальної моделі якості. Ключовим елементом стандарту є Рекомендаційна рамка для опису підходів до якості (the Reference Framework for the Description of Quality Approaches). Стандарт ISO / IEC 19796:2005 складається з трьох частин: ·

- ISO/IEC 19796-1:2005 - Ч. 1: Загальний підхід (Part 1: General approach) перший крок у напрямі побудови гармонізованої моделі якості для навчання на основі IT;

- ISO/IEC 19796-2 - Ч. 2: Гармонізована модель якості (Part 2: Harmonized quality model) - визначає інструменти і метрики 3 метою упровадження загального підходу до якості;

- ISO/IEC 19796-3:2009 - Ч. 3: Рекомендаційні методи та метрика (Part 3: Reference methods and metrics) - розширює межі Рекомендаційної рамки для опису підходів до якості, визначеної в попередній частині стандарту ISO/IEC 19796-1:2005, з упровадженням гармонізованого опису методів та метрики, рекомендованих для впровадження системи забезпечення якості, управління якістю зацікавленими сторонами, які займаються розробленням, розвитком, утилізацією IT систем для навчання, освіти і професійної підготовки.

Проте, більшість вимог стандарту ISO/IEC 19796:2005 стосується лише якості розроблення, розвитку, утилізації ІТ систем для навчання, освіти і професійної підготовки. Тому можна вважати, що міжнародні стандарти теж не розкривають поняття якості електронних освітніх ресурсів та не містять вимог щодо іiі забезпечення. 
Зміст різних видів експертизи під час сертифікації електронного освітнього ресурсу включає попередню та комплексну експертизи.

Попередня експертиза включає програмно-технічну експертизу, яка визначає працездатність електронного освітнього ресурсу як програмного продукту i його сумісність 3 апаратно-програмними комплексами різних конфігурацій; дає оцінку відповідності чинним стандартам та сучасному технічному рівню аналогічних продуктів; визначає стійкість до помилкових чи некоректних дій користувача

Комплексна експертиза включає:

- структурну експертизу, яка передбачає аналіз виконання загальносистемних вимог до електронних освітніх ресурсів, наявності обов'язкових складових та визначення відповідності кожної складової встановленим вимогам;

- наукову експертизу, яка передбачає аналіз застосування сучасних наукових положень, розробок, інформації та посилань на передові наукові праці у матеріалах електронних освітніх ресурсів; оцінюється актуальність змісту, новизна поданого матеріалу, його завершеність і логічна узгодженість;

- методичну експертизу, яка передбачає оцінювання методичних аспектів організації дистанційного курсу, педагогічно-психологічних засад організації навчальної діяльності студентів, організації системи контролю; оцінюється завершеність і логічна узгодженість матеріалу.

Можливості електронних освітніх ресурсів нового покоління забезпечують трансформацію освітніх технологій, основаних на репродуктивній моделі навчання, в напрямку інноваційних технологій активного навчання. Інновації в освітній діяльності визначаються приростом творчого компонента діяльності викладача в аудиторії, переходом від мовлення до дискусії, колективного аналізу і дослідженням за повноцінної і високоефективної самостійної роботи студентів та викладача за межами аудиторії. Таким чином, освітні технології реалізують потенціал відкритих електронних освітніх ресурсів нового покоління у таких напрямах:

- забезпечення всіх компонентів освітнього процесу;

- здійснення особистісно-орієнтованого навчання;

- розвиток активно-дієвих форм навчання;

- розширення функціональності системи та кардинальне підвищення ефективності самостійної навчальної роботи.

Завдяки високій інтерактивності і мультимедійності контенту електронного навчального модуля розвиток активно-дієвих форм навчання переходить у практичну площину впровадження в систему післядипломної освіти, що підтримується моделінгом. 3 урахуванням варіативності модулів діяльності, найефективніші форми навчання можуть поширюватися на будьякого споживача освітньої послуги.

Крім інноваційних і технологічних якостей у системі оцінювання модуля велику роль відіграє традиційна експертиза навчального змісту. Мінімально необхідними при цьому є такі критерії:

- відповідність завданням на виконання робіт;

- відповідність навчального змісту освітньому стандарту (програмі навчання); 
• повна відповідність тематичного елемента предметній області;

- методична ефективність за рахунок доцільного використання інноваційних якостей;

• відповідність сучасним науковим уявленням предметної області;

- відповідність базовим цінностям соціуму;

- адекватність підсумкових даних.

Необхідно зазначити, що інтегральній оцінці якостей створених електронних навчальних модулів передує експертиза концепції електронного освітнього ресурсу в предметній області, узгодження сценарних планів та інших організаційно-правових документів, покладених в основу розроблення відкритої модульної мультимедійної освітньої платформи. Відповідно, параметри і характеристики модуля, встановлені в процесі експертизи як такі, що визначають його інноваційні, технологічні та змістові якості, повинні бути не гірші від заявлених у вихідній документації.

Процедура інтегрального оцінювання якостей електронного навчального модуля розпочинається з моменту реєстрації електронного освітнього ресурсу.

Як випливає 3 концепції моніторингу якості електронного освітнього ресурсу, інтегральна оцінка якостей навчального модуля проходить через досить великий перелік параметрів, що характеризують його інноваційні, технологічні та змістові якості.

Певні якості електронного навчального модуля можна встановити тільки експертизою під час його функціонування. Так, виключно до компетенції експерта належить визначення рівня інтерактивності, якості мультимедійних компонентів, а також оцінювання змістових якостей.

I

Складові інтегрального оцінювання якостей електронних освітніх ресурсів

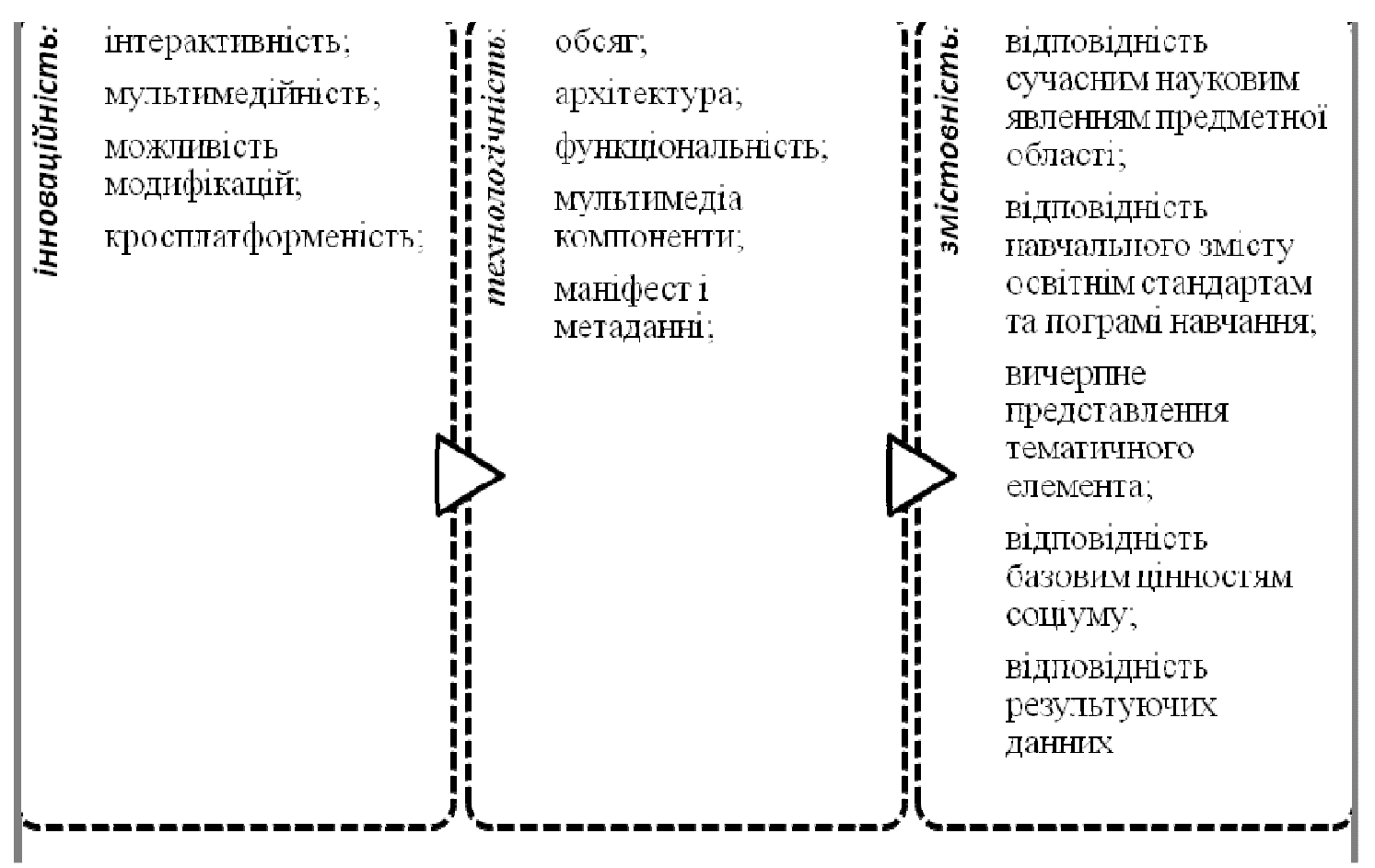

Рис. 1. Модель інтегрального оцінювання якостей електронних освітніх ресурсів 
Відповідно до рис. 1, інтегральне оцінювання якостей електронного навчального модуля розбивається на три етапи. На першому етапі проводиться автоматичний комп'ютерний аналіз структурних складових електронного навчального модуля, що дозволяє отримати попередню або остаточну оцінку більшості технологічних і ряду інноваційних якостей.

На другому етапі експерт - фахівець в області інформаційних технологій проводить функціональну експертизу модуля. В процесі відтворення електронного навчального модуля встановлюються його функціональні можливості і виявляються помилки програмних рішень. Крім того, динамічний режим забезпечує додаткову інноваційно-технологічну експертизу для уточнення даних структурного аналізу, а також дає можливість оцінити інноваційні та технологічні якості, що визначаються тільки в процесі функціонування навчального модуля.

На третьому етапі експерт - фахівець 3 предметної галузі оцінює змістові якості модуля.

Важливими елементами інтегрального оцінювання якостей електронного навчального модуля на кожному процедурному етапі $є$ порядок та критерії оцінювання. При цьому необхідно зазначити, що негативна оцінка будь-якої із якостей модуля на будь-якому етапі не $є$ підставою для припинення процедури оцінювання, яка покликана дати максимальну інформацію для доопрацювання модуля. Винятком є тільки порушення функціональності модуля, які викликані критичними помилками в його архітектурі або програмних рішеннях, що унеможливлює подальшу процедуру оцінювання.

Основною ціллю функціональної експертизи $\epsilon$ аналіз працездатності електронного навчального модуля, перевірка чіткості виконання всіх заявлених функцій. Крім того, при відтворенні модуля завершується експертиза його інноваційних i технологічних якостей: уточняються попередні оцінки структурного аналізу і виносяться оцінки щодо IT-якостей, які визначаються тільки в процесі функціонування модуля.

Функціональне середовище електронного навчального модуля включає кросплатформенні програвач та органайзер, а також сумісність із системним програмним забезпеченням. Під час функціональної експертизи розглядається кожна мультимедійна сцена в електронному навчальному модулі, виявляється непрацездатність (або помилкова робота) тих чи інших мізансцен, мультимедіа композицій, навчальних об'єктів чи процесів, медіаелементів, медіакомбінацій, елементів навігації, маніпуляторів та інших елементів. Визначаються помилки організації інтерактиву - відсутність або неправильна реакція об'єкта чи процесу, невідповідні пропозиції-повідомлення, помилки розміщення об'єктів.

Недопустимими є порушення у функціонуванні електронного навчального модуля, помилки на будь-якому рівні - від модуля в цілому до медіаелементів. Виявлення помилки функціонування $є$ підставою для припинення процедури IBK, модуль повертається на доопрацювання.

У повнофункціональному модулі експертним шляхом встановлюється також: 
- рівень інтерактивності,

- рівень мультимедійності кожної сцени,

- якість мультимедіа компонентів.

Оцінювання інноваційних якостей здійснюється за критеріями i кваліметрією уніфікованих вимог. Якість мультимедіа компонентів визначається суб'єктивно.

Необхідно зауважити, що після визначення рівня мультимедійності кожної навчальної сцени, оцінка рівня мультимедійності модуля, отримана на етапі структурного аналізу, може змінитися. Крім того, оцінка може змінитися на негативну, якщо буде виявлена сцена з рівнем мультимедійності, що дорівнює одиниці. Таким чином, ще одне призначення функціональної експертизи уточнення деяких оцінок комп'ютерного структурного аналізу.

Крім рівня мультимедійності, функціональна експертиза фактично дає остаточну оцінку мультимедійній модульній платформі. Бездоганне функціонування модуля, відтвореного кросплатформним програвачем, дозволяє переконатися у відсутності переносних орієнтованих програмних рішень, прихованих від структурного аналізу. Однак, з огляду на істотні відмінності кваліфікації та технологічної культури розробників, цього може виявитися недостатньо. Для прийняття остаточного рішення слід безпосередньо переконатися у функціональності електронного навчального модуля, відтвореного в середовищі альтернативної операційної системи.

Контроль оригінальних записів у метаданих (опис електронного навчального модуля, його характеристики, авторські права, ключові слова та ін.) - також покладається на експерта. Результати експертного контролю разом iз даними автоматичного аналізу дозволяють дати остаточну оцінку якості метаданих електронного навчального модуля.

Надзвичайну вагу має експертиза змістових якостей навчального модуля, тобто освітньої ефективності мультимедіа продукту. Сучасний стан розвитку електронного освітнього контенту характеризується істотним просуванням у формалізації критеріїв оцінювання, кваліметрії інноваційних і технологічних якостей електронного освітнього ресурсу, визначенням розуміння освітньої цінності продукту. Однак, у сучасній експертизі перейшли від читання символьних описів до безпосереднього вивчення об'єктів і процесів предметної області.

У цих умовах експертиза змістових якостей електронного навчального модуля повинна використовувати систему прозорих критеріїв 3 мінімальними можливостями трактування. Проте, не можливо забувати про педагогіку, яка значною мірою - мистецтво i, як будь-яке мистецтво, невіддільна від творця, простіше кажучи - суб'єктивна. Виходом в такій ситуації може бути тільки навмисна відмова від очевидно дискусійних формулювань критеріїв оцінювання.

У рамках експертизи змістових якостей електронного навчального модуля фахівець предметної області повинен дати оцінку контенту електронного навчального модуля, виходячи 3 таких критеріїв як відповідність сучасним 
науковим уявленням предметної області; відповідність навчального змісту освітньому стандарту (програмі навчання); вичерпне уявлення тематичного елемента; методична ефективність за рахунок доцільного використання інноваційних якостей; відповідність базовим цінностям соціуму; адекватність підсумкових даних.

Уніфікованими вимогами концепції оцінювання електронного навчального модуля визначені можливі варіанти розв'язання завдань особистісно орієнтованого навчання у відкритій освітній модульній мультимедійній системі. Виходячи 3 уніфікованих вимог, слід розрізняти варіативні модулі, що розміщуються в центральному сховищі системи, підготовлені професійними розробниками, і модулі, модифіковані користувачами під власні запити.

Оцінити якість навчального електронного освітнього ресурсу неможливо без урахування думки споживачів освітньої послуги. Більшість ключових критеріїв, які використовують для оцінювання електронних освітніх ресурсів, не завжди чітко визначають навчальну ефективність оцінюваного програмного пакета. Отримання достовірної інформації про роботу електронного освітнього ресурсу є результатом включення студентів у процес оцінювання.

Для оцінювання електронного освітнього ресурсу використано модель Рейзера та Діка [15], що зосереджена на тому, наскільки студенти отримують нові навички, якими наділений пакет програмного забезпечення електронного навчального модуля - моделінг. Використовуючи цей підхід, викладачі зможуть краще визначати електронні навчальні модулі, які ефективно навчають.

Висновки та перспективи подальших досліджень. Розроблена система оцінювання електронних освітніх ресурсів передбачає інтегральне оцінювання якостей кожного окремого навчального модуля. Вона містить параметри, що характеризують інноваційні, технологічні та змістові якості навчального модуля. Така система оцінювання електронних освітніх ресурсів дозволяє:

1. Оцінити та проконтролювати як окремі навчальні модулі, так і всю навчальну систему в цілому.

2. Перейти від оцінювання окремих процесів та елементів у навчальному модулі, до модульного структурно-цільового (інтегрального), орієнтованого на особистість фахівця, що навчається в системі післядипломної освіти.

3. Ввести систему інтегрального оцінювання якості освітніх ресурсів та ефективності діяльності споживача освітніх послуг, передавши контроль за величинами на рівень системи через вбудований модуль контролю за освітньою діяльністю. Зручність інтегральних оцінок полягає в тому, що вони дають єдиний числовий критерій якості.

4. Ініціювати поступове розширення в усіх напрямах відкритого електронного освітнього ресурсу по мірі впровадження нових показників освітньої педагогічної системи. 


\section{ЛІТЕРАТУРА}

1. Биков В.Ю. Методологічні та методичні основи створення і використовування електронних засобів навчального призначення / В.Ю.Биков., В.В.Лапінський // Комп’ютер у школі та сім’ї №2(98), 2012. - С.3-6.

2. Вембер В. П. Інформатизація освіти та проблеми впровадження педагогічних програмних засобів в навчальний процес / В. П. Вембер // Інформаційні технології і засоби навчання [Електронний ресурс]. - 2007. - № 2(3). - Режим доступу : http : //www.ime.eduua.net/em3/emg.html - Заголовок з екрана.

3. Вострокнутов И.Е. Теория и технология оценки качества программных средств образовательного назначения / И.Е.Вострокнутов. - М.: Госкоорцентр информационных технологий, 2005. - 300 с.

4. Гура В.В. Теоретические основы педагогического проектирования личностноориентированных электронных образовательных ресурсов и сред / В.В. Гура. [Електронний pecypc]. - 2007. - Режим доступу : http://www.dissercat.com/content/teoreticheskieosnovypedagogicheskogo-proektirovaniya-lichnostno-orientirovannykh-elektronn - Заголовок з екрана.

5. Кравцов Г.М. Про критерії оцінювання якості електронних навчальних ресурсів / Г.М. Кравцов. [Електронний ресурс]. - 2010. - Режим доступу: http://zavantag.com/tw_files2/urls_6/298/d-297134/7z-docs/5.pdf - Заголовок з екрана.

6. Морзе Н.В. Критерії якості електронних навчальних курсів, розроблених на базі платформ дистанційного навчання / Н.В. Морзе, О.Г. Глазунова // Інформаційні технології в освіті: Зб. наук. праць. Випуск 4. - Херсон: ХДУ, 2009. - С.63-75

7. Роберт И.В. Теория и методика информатизации образования (психологопедагогический и технологический аспекты) / И.В.Роберт. - М.: ИИО РАО, 2008. - 274 с.

8. Наказ Міністерства освіти та науки, молоді та спорту України від 01.10.2012 № 1060 Про затвердження положення про електронні освітні ресурси [Електронний ресурс]. - Режим доступу : http://zakon5.rada.gov.ua/laws/show/z1695-12. - Назва з екрана.

9. ДСТУ 7157:2010. Інформація та документація. Видання електронні. Основні види та вихідні відомості. - Чинний від 2010-07-01. - К. : Держспоживстандарт України, 2010. - 13 с.

10. ДСТУ 4861:2007 Інформація та документація. Видання. Вихідні відомості. - Чинний 2009.01.01. - К.: Держспоживстандарт України, 2009. - 45 с.

11. ДСТУ 3017-95 Видання. Основні види. Терміни та визначення. - Чинний від 199601-01. - К. : Держстандарт України, 1995. - 47 с:

12. ISO/IEC 19796-1:2005 Information technology -- Learning, education and training Quality management, assurance and metrics - Part 1: General approach [Електронний ресурс]. Режим доступу : http://www.iso.org/iso/catalogue_detail?csnumber=33934. - Назва з екрана

13. Сироткін Г.В. Модель системи інтегральної оцінки якості освіти і ефективності діяльності внз // Інновації в науці: зб. ст. по матер. XLVI міжнар. наук.-практ. конф. № 6 (43). - Новосибірськ: СібАК, 2015.

14. IEEE Learning Technology Standards Committee. WG 12: Learning Object Metadata http://ltsc.ieee.org/wg 12

15. Kelly B. Reflections on CETIS's "Future of Interoperability" Meeting. http://ukwebfocus.wordpress.com/2010/01/14/reflections-on-future-of-interoperability-standards-meeting

16. Sharable Content Object Reference Model (SCORM) - Advanced Distributed Learning Initiative. http://www.adlnet.org/Technologies/Scorm/default.aspx

17. Sharable Content Object Reference Model (SCORM) 2004. / Перевод с англ. Е.В. Кузьминой. - М.: ФГУ ГНИИ ИТТ «Информика», 2005, http://www.edu.ru/db/portal/elibrary/00000053/SCORM-2004.pdf

\section{REFERENCES}

1. Bykov V.Yu. Methodological and methodical bases for the creation and use of electronic teaching aids [Methodological and methodical foundations for the creation and use of electronic teaching aids] / V.Yu.Bikov, V.V.Lapinsky // Computer at school and family №2 (98), 2012. - C.3-6 (in Ukrainian).

2. Vember V.P. Informatization of education and the problems of introducing pedagogical software tools into the educational process [Informatization of education and problems of introducing 
pedagogical software tools into the educational process] / VP Vember // Information technologies and teaching aids [Electronic resource]. - 2007. - No. 2 (3). - Mode of access: http: //www.ime.eduua.net/em3/emg.html - Title from the screen (in Ukrainian).

3. Vostroknutov IE Theory and technology of estimation of quality of software of educational purposes [Theory and technology of estimation of quality of software of educational purposes] / IE Vostroknutov. - M .: State Center of Information Technologies, 2005. - 300 p. (in Russia).

4. Gur V.V. Theoretical Foundations of Pedagogical Designing of Personally Oriented Electronic Educational Resources and Mediums [Theoretical bases of pedagogical designing of personal-oriented electronic educational resources and environments] / VV Guru [Electronic resource]. - 2007. - Access mode: http://www.dissercat.com/content/teoreticheskieosnovypedagogicheskogo-proektirovaniya-lichnostno-orientirovannykh-elektronn - Title from the screen (in Russia).

5. Kravtsov GM On the criteria for assessing the quality of electronic learning resources [On the criteria for assessing the quality of electronic learning resources] / G.M. Kravtsov [Electronic resource]. - 2010. - Access mode: http://zavantag.com/tw_files2/urls_6/298/d-297134/7z-docs/5.pdf - Title from the screen (in Ukrainian).

6. Morse N.V. Criteria for quality of electronic training courses, developed on the basis of distance learning platforms [Criteria for the quality of e-learning courses developed on the basis of distance learning platforms] / N.V. Morse, O.G. Glazunova // Information technologies in education: Zb. sciences works. Issue 4. - Kherson: KSU, 2009. - p.63-75 (in Ukrainian).

7. Robert I.V. Theory and method of informatization of education (psychological and pedagogical and technological aspects) [Theory and method of informatization of education (psychological and pedagogical and technological aspects)] / I.V.Robert. - M .: IAO RAO, 2008. 274 p. (in Ukrainian).

8. Order of the Ministry of Education and Science, Youth and Sports of Ukraine dated 10/01/2012 № 1060 On Approval of the Provision on Electronic Educational Resources [Electronic resource]. - Mode of access: http://zakon5.rada.gov.ua/laws/show/z1695-12. - Title from the screen (in Ukrainian).

9. DSTU 7157: 2010. Information and documentation. Electronic edition. Basic Types and Output Details. - Valid from 2010-07-01. - K .: Derzhspozhyvstandart of Ukraine, 2010 - 13 p. (in Ukrainian).

10. DSTU 4861: 2007 Information and documentation. Edition. Output information. Effective 01.01.2009. - K .: Derzhspozhyvstandart of Ukraine, 2009. - 45 p. (in Ukrainian).

11. DSTU 3017-95 Edition. The main types. Terms and definitions. - Effective from 01/01/1996. [ DSTU 7157: 2010. Information and documentation. Electronic edition. Basic Types and Output Details.] - K.: Gosstandart of Ukraine, 1995. - 47 s. (in Ukrainian).

12. ISO / IEC 19796-1: 2005 Information technology - Learning, education and training Quality management, assurance and metrics - Part 1: General approach. - Access mode: [ISO/IEC 19796-1:2005 Information technology - - Learning, education and training - Quality management, assurance and metrics - Part 1: General approach ] http://www.iso.org/iso/catalogue_detail? Csnumber $=33934$. - Title from the screen

13. Sirotkin G.V. Model of the system of integral evaluation of the quality of education and the effectiveness of the activities of universities [The model of the system of integral assessment of the quality of education and the effectiveness of the work of the] // Innovations in science: Sb. Art. by mothers XLVI International science-practice conf. No. 6 (43). - Novosibirsk: SibAc, 2015 (in Russia).

14. IEEE Learning Technology Standards Committee. WG 12: Learning Object Metadata [IEEE Learning Technology Standards Committee. ] http://ltsc.iee.org/wg 12

15. Kelly B. Reflections on CETIS's "Future of Interoperability" Meeting. [Reflections on CETIS's "Future of Interoperability" Meeting.] http://ukwebfocus.wordpress.com/2010/01/14/reflections-on-futureof-interoperability-standards-meeting

16. Sharable Content Object Reference Model (SCORM) - Advanced Distributed Learning Initiative. http://www.adlnet.org/Technologies/Scorm/default.aspx

17. Sharable Content Object Reference Model (SCORM) 2004. / Perevod s angl. E.V. Kuz`my`noj. - M.: FGU GNY`Y` Y'TT «Y`nformy`ka», 2005, http://www.edu.ru/db/portal/elibrary/00000053/SCORM-2004.pdf 


\section{PЕЗЮМЕ}

Анна Кашина,

кандидат педагогических наук Национальный педагогический университет имени М. П. Драгоманова

\section{Методика оценивания качества электронных учебных ресурсов в системе последипломного педагогического образования}

В исследовании рассматриваются вопросы проблемы оченивания качества электронных образовательных ресурсов. Ее сложность повышается за счет того, что интерактивный мультимедийный контент отображает новейшие достижения в отрасли информационных систем и компьютерной техники на содержание учебной дисциплины, образовывая инновачионные качества электронных образовательных ресурсов. Поэтому путяли повышения качества оченивания электронных образовательных ресурсов являются развитие системы критериев, совершенствования квалиметрии, унификация технологий и прочедур, добавления оченки потребителей образовательной услуги.

Ключевые слова: электронный учебный ресурс; экспертиза; экспертная оценка; интегральная оценка

\section{SUMMARY}

Ganna Kashina,

Candidate of Pedagogic Sciences National pedagogical university to the name of M. P. Dragomanowa

Methodology of evaluation of the quality of electronic learning resources in the system of postgraduate pedagogical education

Introduction The problem of assessing the quality of electronic educational resources (EER) is increasing due to the fact that interactive multimedia content reflects the latest achievements in the field of information systems in the content of discipline, creating the innovative qualities of the EER.

Purpose The purpose of the study is to develop a methodology for assessing the quality of EER, taking into account their innovation.

Methods At present, the EER quality assessment task has been decided solely on the basis of expert judgment. A comprehensive examination involves a three-dimensional evaluation of the EER, based on an ergonomic examination of technology, content and design. However, expert assessments have drawbacks: uncertainty of criteria, poor qualimetry, uncertainty of technology, subjectivity of an expert.

Results The proposed evaluation methodology EER provides an integral assessment by the expert of the qualities of each individual training module and contains parameters characterizing the innovative, technological and content quality of the training module.

Originality The developed EER evaluation method allows to evaluate and control both individual training modules and the entire educational system as a whole; move from evaluating individual processes and elements in the training module to an integral, focused on the personality of a specialist trained in the system of postgraduate education.

Conclusion The proposed methodology for evaluating modern EER provides the introduction of an integrated assessment system for the quality of EER and the effectiveness of consumer education services by passing control over the values to the system level through the integrated control module for educational activities. In further research, it is necessary to initiate the extension of the evaluation methodology in all areas of the open e-learning resource as the new indicators of the educational pedagogical system are introduced.

Key words: e-learning resource; expertise; expert assessment; integral assessment 